\title{
Low-frequency Stimulation Erases LTP through an NMDA Receptor-mediated Activation of Protein Phosphatases
}

\author{
Thomas J. O'Dell ${ }^{1,2}$ and Eric R. Kandel ${ }^{1}$ \\ ${ }^{1}$ Howard Hughes Medical Institute \\ Center for Neurobiology and Behavior \\ College of Physicians and Surgeons of Columbia University \\ New York, New York 10032 \\ ${ }^{2}$ Department of Physiology \\ University of California at Los Angeles \\ Los Angeles, California 90024
}

\begin{abstract}
In the CA1 region of adult guinea pig hippocampal slices, long trains of $\theta$ frequency $(5 \mathrm{~Hz})$ stimulation produced a small enhancement of basal synaptic transmission but depressed the strength of synaptic transmission at synapses that had recently undergone long-term potentiation (LTP). Five hertz stimulation delivered immediately prior to high-frequency stimulation also inhibited the subsequent induction of LTP. The depression of potentiated synapses by $5 \mathrm{~Hz}$ stimulation (depotentiation) was blocked by 2-amino-5-phosphonovalerate and was observed only during the early phases of LTP. Furthermore, the protein phosphatase inhibitors okadaic acid and calyculin A blocked both depotentiation and the ability of $5 \mathrm{~Hz}$ stimulation to inhibit subsequent LTP, suggesting that protein phosphatases are involved in the ability of $5 \mathrm{~Hz}$ stimulation to modulate synaptic plasticity in the CA1 region of the hippocampus.
\end{abstract}

\section{Introduction}

The strength of excitatory synaptic transmission in the CA1 region of the hippocampus can be both increased and decreased by patterns of synaptic activity that activate postsynaptic $N$-methylD-aspartate (NMDA)-type glutamate receptors (for review, see Malenka and Nicoll 1993). Following strong activation of NMDA receptors by high-frequency presynaptic fiber stimulation, synaptic transmission undergoes a persistent enhancement known as long-term potentiation (LTP) (Bliss and Collingridge 1993). In addition to being a prominent feature of synaptic transmission in regions of the brain important for memory storage, several features, especially its persistence, have made LTP an attractive candidate for a cellular mechanism involved in the storage of long-term memory. However, the very persistence of LTP is itself problematical, as it could lead to a saturation of all modifiable synapses in a potentiated state making it impossible to store further memories. It has thus been suggested that in addition to a process like LTP, there must also be mechanisms capable of decreasing the strength of synaptic transmission (Sejnowski 1977; Bienenstock et al. 1982; Wilshaw and Dayan 1990; Tsumoto 1993). Consistent with the idea that LTP must coexist with processes that decrease synaptic strength, excitatory synaptic inputs onto CA1 pyramidal cells have now been shown to undergo depression following long trains of low-frequency $(1-3 \mathrm{~Hz})$ presynaptic stimulation (Dudek and Bear 1992; Mulkey and Malenka 1992). This form of long-term depression (LTD) is homosynaptic and, like LTP, dependent on both NMDA receptor activation and increases in intracellular $\mathrm{Ca}^{2+}$ for its induction (Dudek and Bear 1992; Mulkey and Malenka 1992). Furthermore, inhibitors of protein phosphatases block homosynaptic LTD of basal synaptic transmission, suggesting that protein phosphatase activation may be an important component of the signaling pathways responsible for LTD (Mulkey et al. 1993).

While homosynaptic LTD is robust in young animals (Mulkey and Malenka 1992; Dudek and Bear 1993), it is not in adult animals. Long trains of

LEARNING \& MEMORY 1:129-139 (C) 1994 by Cold Spring Harbor Laboratory Press ISSN1072-0502/94 \$5.00

$$
\begin{array}{llllllll}
L & E & A & R & N & I & N & G \\
\hline & \mathbf{Q} & M & E & M & O & R & Y
\end{array}
$$


low-frequency stimulation produce little or no depression of basal excitatory synaptic transmission in the CA1 region of the hippocampus in adult animals (Barrionuevo et al. 1980; Staubli and Lynch 1990; Fujii et al. 1991; Larson et al. 1993). Thus homosynaptic LTD may be primarily important during early stages of postnatal neuronal development, and other processes that decrease the strength of excitatory synaptic transmission may be operative in the mature hippocampus. Low-frequency stimulation protocols that have little effect on the strength of basal synaptic transmission in the adult hippocampus can depress the strength of synaptic transmission at synapses that have recently undergone LTP, a phenomenon known as depotentiation (Barrionuevo et al. 1980; Stabuli and Lynch 1990; Larson et al. 1993; Fujii et al 1991). Depotentiation shares some features with LTD studied in young animals, perhaps indicating that the biochemical processes responsible for LTD and depotentiation are similar. For instance, both LTD and depotentiation are produced by long periods of low-frequency stimulation, generally several hundred pulses delivered at 1-5 $\mathrm{Hz}$. Moreover, like LTD, depotentiation is blocked by the the NMDA receptor antagonist 2-amino-5phosphonovaleric acid (APV), suggesting that NMDA receptor activation, and perhaps increases in intracellular $\mathrm{Ca}^{2+}$, are important for decreasing the strength of synaptic transmission at synapses that have recently undergone LTP (Fujii et al. 1991). However, the observation that depotentiation is present even in the adult hippocampus where LTD is apparently absent suggests that LTD and depotentiation may be distinct processes, or important variants of a common process, that are differentially expressed during developement. To better understand the cellular mechanisms of depotentiation and to determine whether these mechanisms are similar to those responsible for LTD of basal synaptic transmission in younger animals, we have investigated the ability of low-frequency stimulation protocols to modify the strength of synaptic transmission in slices of adult guinea pig hippocampus where homosynaptic LTD of basal synaptic transmission is absent (Fujii et al. 1991).

\section{Materials and Methods}

Standard techniques were used to prepare $400-\mu m$-thick hippocampal slices from 3 - to 8-week-old male guinea pigs or 13- to 19-day-old rats. Slices were kept in an interface recording chamber containing an artificial cerebrospinal fluid (ACSF) consisting of (in $\mathrm{mM}$ ) $124 \mathrm{NaCl}, 4.4$ $\mathrm{KCl}, 25 \mathrm{NaHCO}_{3}, 1.0 \mathrm{Na}_{2} \mathrm{H}_{2} \mathrm{PO}_{4}, 2.0 \mathrm{CaCl}_{2}, 2.0$ $\mathrm{MgSO}_{4}$, and 10 glucose. The chamber was perfused at $1-3 \mathrm{ml} / \mathrm{min}$ with oxygenated $\left(95 \% \mathrm{O}_{2} /\right.$ $\left.5 \% \mathrm{CO}_{2}\right) \mathrm{ACSF}$, and the temperature was maintained at $30^{\circ} \mathrm{C}$. Synaptic transmission in the CA1 region of the hippocampus was monitored by stimulating presynaptic fibers in stratum radiatum (at $0.02 \mathrm{~Hz}$ ) with bipolar nichrome or tungsten wire electrodes (0.01- to $0.02-\mathrm{msec}$ duration pulses ) and recording postsynaptic potentials using an extracellular glass microelectrode filled with ACSF (5-10 M $\Omega$ resistance). Prior to each experiment the maximal amplitude of the field excitatory postsynaptic potentials (EPSPs) was determined, and the intensity of presynaptic stimulation was adjusted to evoke a postsynaptic response equal to $20-30 \%$ of the maximum except in experiments examining LTD in slices from young rat hippocampus, where the intensity of presynaptic fiber stimulation was adjusted to evoke a postsynaptic response equal to $\sim 50 \%$ of the maximum. LTP was induced using two 1-sec-long trains of $100 \mathrm{~Hz}$ stimulation delivered $20 \mathrm{sec}$ apart at a stimulation intensity sufficient to elicit an EPSP that was $75 \%$ of the maximal amplitude. Field EPSPs mediated by the NMDA type glutamate receptor were examined by blocking non-NMDA receptors with $20 \mu \mathrm{M}$ 6-cyano-7-nitroquinoxaline-2,3dione or $25 \mu \mathrm{M}$ 6,7-dinitroquinoxaline-2,3-dione, and blocking inhibitory synaptic transmission with 50-100 $\mu \mathrm{M}$ picrotoxin. In these experiments the CA3 region of the slice was removed and the ACSF contained $3.0 \mathrm{~mm} \mathrm{CaCl}_{2}$ and $1.0 \mathrm{~mm} \mathrm{MgSO}_{4}$. Intracellular recordings of IPSPs were done in normal ACSF using high resistance (40-100 M $\Omega$ resistance, $2 \mathrm{M}$ potassium methylsulfate) glass microelectrodes to impale single CA1 pyramidal cells. Only cells with stable membrane potentials more negative than $-60 \mathrm{mV}$ and input resistance's $>30$ $\mathrm{M} \Omega$ were used. All values in the text and in the figures are reported as mean \pm s.E.M., and in all figures showing average data only every other time point is shown for clarity. Student's $t$-tests were used to access statistical significance.

\section{Results}

Low-frequency synaptic stimulation that produces homosynaptic LTD of excitatory synaptic

$$
\text { ……" }
$$


transmission in the CA1 region of the immature rodent hippocampus (Dudek and Bear 1992; Mulkey and Malenka 1992; Bolshakov and Siegelbaum 1994) has no effect on synaptic efficacy in hippocampal slices obtained from adult guinea pigs (Fujii et al. 1991). Consistent with the findings reported by Fujii et al. (1991), we observed that excitatory synaptic transmission in the CA1 region of the adult guinea pig hippocampus is not depressed following 900 pulses of $1 \mathrm{~Hz}$ stimulation (Fig. 1). EPSPs $45 \mathrm{~min}$ after $15 \mathrm{~min}$ of $1 \mathrm{~Hz}$ stimulation were $109 \pm 6.3 \%(n=7)$ of pre-1 Hz control levels. Nine hundred presynaptic stimulation pulses delivered to the Schaffer collateral/
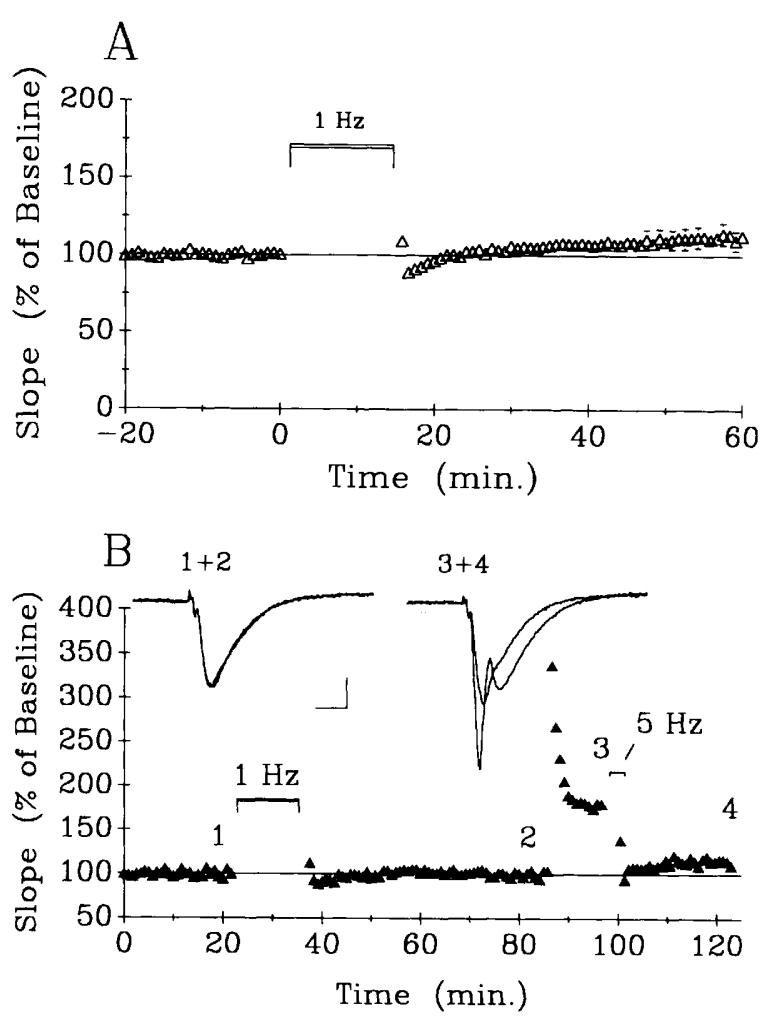

Figure 1: Long-term depression is not evoked by $1 \mathrm{~Hz}$ stimulation in hippocampal slices from adult guinea pigs. (A) No depression of synaptic transmission is seen following 900 pulses of $1 \mathrm{~Hz}$ stimulation delivered beginning at time zero. Values are mean \pm S.E.M., $n=7$. (B) Results from one of the seven experiments shown in $A$ where LTP was induced by two trains of $100 \mathrm{~Hz}$ stimulation delivered $\sim 50 \mathrm{~min}$ after $1 \mathrm{~Hz}$ stimulation. Ten minutes after high-frequency stimulation, 900 pulses of $5 \mathrm{~Hz}$ stimulation produced depotentiation in the same slice where 900 pulses of $1 \mathrm{~Hz}$ stimulation failed to produce LTD of basal synaptic transmission. The EPSPS were recorded at the times indicated by the numbers. Scale bars are $5 \mathrm{msec}$ and $1 \mathrm{mV}$. commissural fibers at $\theta$ frequency ( $5 \mathrm{~Hz}$ ), which induces a homosynaptic, NMDA receptor-independent LTD of synaptic transmission in 3- to 7-dayold animals (Bolshakov and Siegelbaum 1994), also failed to elicit LTD in adult slices but instead produced a small and persistent enhancement of synaptic transmission (Fig. 3B, below), whereby the field EPSP at $30 \mathrm{~min}$ was increased to $118.33 \pm 5.8 \%$ of baseline $[n=6, t(5)=2.28$; $P<0.05$ compared with pre $-5 \mathrm{~Hz}$ baseline]. In contrast, 900 stimulation pulses at $5 \mathrm{~Hz}$ produced a pronounced depression of synaptic transmission (depotentiation) when given following the induction of LTP by tetanic stimulation ( $100 \mathrm{~Hz}$ ) (Fig. 1B, see also Fujii et al. 1991; Larson et al. 1993). Nine hundred stimulation pulses at $5 \mathrm{~Hz}$ given at either 7 or $17 \mathrm{~min}$ post-tetanus reduced LTP, measured at 60 min post-tetanus, by $50 \%$ or more. Compared with control LTP levels (190.8 $\pm 10.9 \%$, $\boldsymbol{n}=9), 5 \mathrm{~Hz}$ stimulation at $7 \mathrm{~min}$ reduced LTP to $143.85 \pm 10.9 \%$ of baseline $[n=10, t(17)=3.05$; $P<0.01$ compared with control LTP $]$ and at $17 \mathrm{~min}$ (Fig. 2C) it reduced LTP to $140 \pm 16.7 \%$ of baseline $[n=11, t(18)=2.42 ; P<0.05$ compared with control LTP]. In contrast to the clear depotentiation obtainable within the first $20 \mathrm{~min}$ following the induction of LTP, LTP was resistant to depotentiation produced by $5 \mathrm{~Hz}$ stimulation at $60 \mathrm{~min}$ after induction (Fig. 3; Fujii et al. 1991). The duration of this time "window" for inducing depotentiation may depend on the stimulation frequency used to induce depotentiation, since Fujii et al. (1991) find that with $1 \mathrm{~Hz}$ stimulation depotentiation is reduced compared with earlier time points but still evident $100 \mathrm{~min}$ after inducing LTP (Fujii et al. 1991).

The ability of $5 \mathrm{~Hz}$ stimulation to depress selectively only potentiated and not basal synaptic transmission does not simply result from the increase in the size of the postsynaptic response following the induction of LTP. Five hertz stimulation caused no depression of basal synaptic transmission in experiments where a comparable doubling of the basal response amplitude was achieved by increasing the stimulation strength (EPSPs were $99.8 \pm 7.8 \%$ of baseline, $n=5,30 \mathrm{~min}$ post- $5 \mathrm{~Hz}$ stimulation).

Although a train of 900 pulses at $5 \mathrm{~Hz}$ stimulation has no inhibitory effect on basal synaptic transmission, it is similar in frequency and number of pulses to those that do produce LTD in young animals. Because LTD in these young animals can be prevented by antagonists of the NMDA recep-






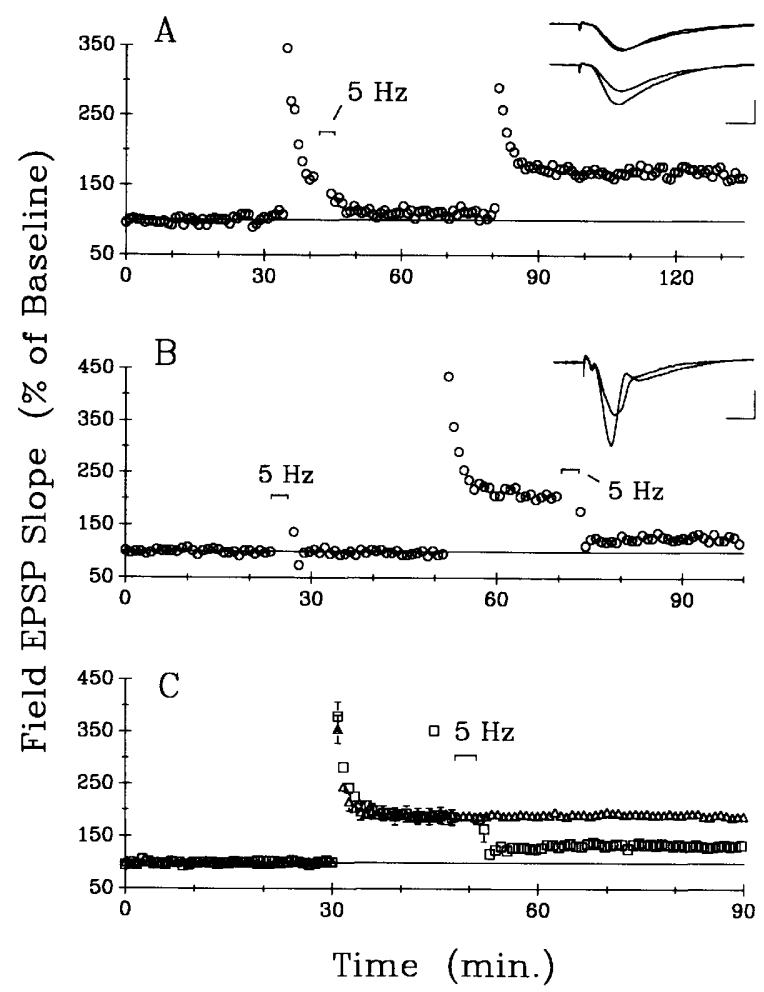

Figure 2: Effects of $5 \mathrm{~Hz}$ stimulation on potentiated synaptic transmission. (A) Results from an individual experiment showing depotentiation induced by $5 \mathrm{~Hz}$ stimulation delivered beginning $7 \mathrm{~min}$ (bracket) post-tetanic stimulation. A second set of $100 \mathrm{~Hz}$ stimulation trains not followed by $5 \mathrm{~Hz}$ stimulation produced clear LTP in the same slice. (Inset) Traces of individual EPSPs recorded just before and $30 \mathrm{~min}$ after tetanic stimulation followed by $5 \mathrm{~Hz}$ stimulation (top) and just before and $40 \mathrm{~min}$ after the second tetanus (larger response, bottom). Scale bars, $1.0 \mathrm{mV}$ and $3 \mathrm{msec}$. (B) Results from another individual experiment showing the effects of 5 $\mathrm{Hz}$ stimulation on basal and potentiated (beginning 17 min after high-frequency stimulation) synaptic transmission. (Inset) Two EPSPs recorded just prior to (larger response) and $30 \mathrm{~min}$ after $5 \mathrm{~Hz}$ stimulation of potentiated synapses. Scale bars, $1.0 \mathrm{mV}$ and $3 \mathrm{msec}$. (C) Summary of experiments where 900 pulses of $5 \mathrm{~Hz}$ stimulation were delivered between 17 and 20 min post-tetanus $(\square$, $n=5$ ). Control LTP experiments showing normal LTP (no $5 \mathrm{~Hz}$ stimulation) are shown for comparison $(\triangle, n=9)$.

tor (Dudek and Bear 1992; Mulkey and Malenka 1992), we then examined whether NMDA receptor activation is required for depotentiation by applying $50 \mu \mathrm{M} \mathrm{APV} \mathrm{in} \mathrm{the} \mathrm{bath} \mathrm{before} \mathrm{attempting} \mathrm{to}$ elicit depotentiation. In the presence of APV, $5 \mathrm{~Hz}$ stimulation had no effect on potentiated synaptic transmission measured $60 \mathrm{~min}$ post-tetanus (Fig. $4 \mathrm{~A}$, below), indicating that depotentiation re- quires NMDA receptor activation $([t(15)=0.31$; not significant compared with control LTP]; see also Fujii et al. 1991).

How is depotentiation induced? Because $5 \mathrm{~Hz}$ stimulation seems unlikely to produce sufficient temporal summation of the EPSPs to provide the depolarization necessary to reduce the voltage-dependent $\mathrm{Mg}^{2+}$ ion block of the NMDA receptor
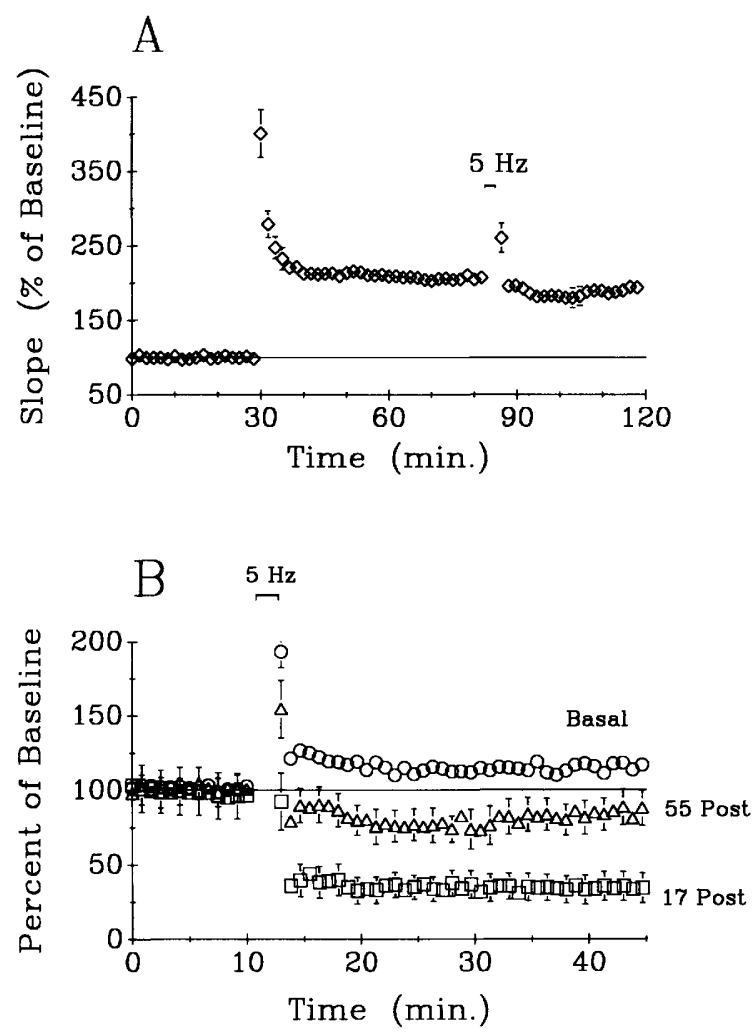

Figure 3: (A) $5 \mathrm{~Hz}$ stimulation delivered beginning 55 min post-tetanus has little effect on potentiated synaptic transmission. Sixty minutes post-tetanus, responses were $186 \pm 9.9 \%$ of pretetanus control levels, mean \pm S.E.M., $n=7$, and not significantly different from experiments where no $5 \mathrm{~Hz}$ stimulation was delivered $[t(14)=0.32$; not significant)] (B) Five Hertz stimulation has opposite effects on synaptic efficacy depending on whether synapses are in a basal or potentiated state. Comparison of the effects of $5 \mathrm{~Hz}$ stimulation on basal $(O, n=6)$ and potentiated synaptic transmission when delivered beginning 17 min post-tetanus $(\square, n=11)$ or 55 min posttetanus $(\triangle, n=7)$. For the results of experiments where $5 \mathrm{~Hz}$ stimulation was delivered to potentiated synapses the responses were normalized to the average of the responses evoked over the last $10 \mathrm{~min}$ preceding the 5 $\mathrm{H}_{z}$ stimulation. Note that the effects of $5 \mathrm{~Hz}$ stimulation not only depend on whether synaptic transmission is potentiated or not but also on the time interval following the induction of LTP.






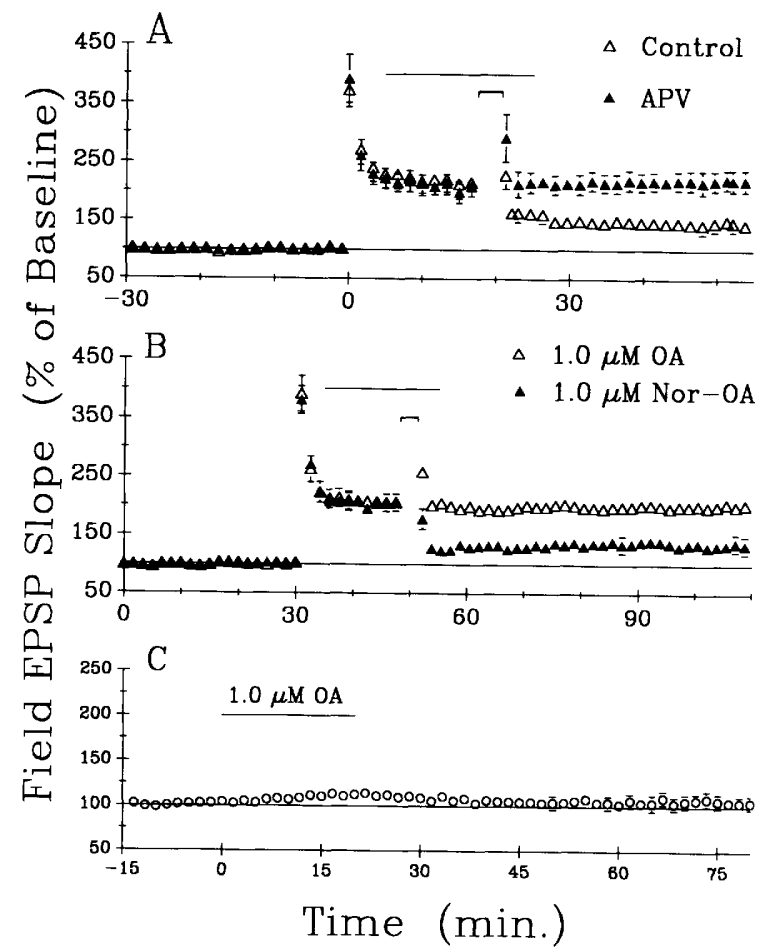
ment of synaptic transmission that did not persist following pre-okadaic acid baseline, $[n=7, t(6)=0.43$, not significant].

ion channel, how do low frequencies of stimulation activate the NDMA receptor? One possibility is that because the $\mathrm{Mg}^{2+}$ block of the NMDA receptor ion channel is not complete at negative membrane potentials, small amounts of $\mathrm{Ca}^{2+}$ influx through synaptic NMDA receptor ion channels may be sufficient to elicit depotentiation (e.g., see Sah et al. 1989). Because Schaffer collateral/ commisural fiber stimulation also evokes fast GABA receptor-mediated inhibitory postsynaptic potentials (IPSPs) that normally coincide with and oppose the NMDA receptor-mediated component of the EPSPs, another process that may aid NMDA receptor activation during low-frequency stimulation is the decrease in inhibitory synaptic transmission that occurs during low-frequency stimulation in the hippocampus (McCarren and Alger 1985; Davies et al. 1991; Mott and Lewis 1991; Pacelli et al. 1991; Wilcox and Dichter 1994). To address this point, we examined inhibitory synaptic transmission using intracellular recordings and found it to be extremely labile and to fade rapidly during $5 \mathrm{~Hz}$ stimulation. Following $3 \mathrm{~min}$ of $5 \mathrm{~Hz}$ stimulation pulses, fast IPSPs were reduced by $>80 \%$ of control (control $=6.7 \pm 1.2 \mathrm{mV}$; post-5
Figure 4: NMDA receptor antagonists and inhibitors of protein phosphatases block depotentiation. (A) The NMDA receptor antagonist APV blocks depotentiation. Control experiments showing normal depotentiation produced by $5 \mathrm{~Hz}$ stimulation (bracket) between 17 and 20 min post-tetanus $(\triangle, n=6)$. No depotentiation was observed when $50 \mu \mathrm{M}$ D, L-APV was present in the bath (indicated by the bar) from $5 \mathrm{~min}$ post-tetanus to 5 min after $5 \mathrm{~Hz}$ stimulation $(\boldsymbol{\Lambda}, n=8)$. (B) $1.0 \mu \mathrm{M}$ okadaic acid (in $0.1-0.2 \%$ DMSO-containing ACSF) bath applied for 20 min beginning 5 min post-tetanus (bar) completely prevented the depotentiating effect of 900 pulses of $5 \mathrm{~Hz}$ stimulation (bracket) delivered between 17 and 20 min post-tetanus $(\triangle$, $n=8$ ). At 60 min post-tetanus, responses were $200.3 \pm 11.8 \%$ of baseline (mean \pm S.E.M.) and not significantly different from the amount of potentiation seen in control LTP experiments [no $5 \mathrm{~Hz}$ stimulation, $t(15)=0.59$, not significant] but significantly greater than in experiments where $5 \mathrm{~Hz}$ stimulation was delivered in the absence of okadaic acid $[t(17)=2.73$; $P<0.05]$. The inactive okadaic acid analog nor-okadaone (in $0.2 \%$ DMSO) at the same concentration had no effect on depotentiation $(\boldsymbol{\Delta}, n=5)$. Responses at $60 \mathrm{~min}$ post-tetanus in experiments where $5 \mathrm{~Hz}$ stimulation was delivered beginning $17 \mathrm{~min}$ post-tetanus in the presence of nor-okadaone were $147.03 \pm 11.9 \%$ of baseline and not significantly different from $5 \mathrm{~Hz}$ alone delivered at 17 min post-tetanus, $[t(16)=0.231$,
okadaic acid (indicated by the bar) produced a small enhance-
$\mathrm{Hz}=0.98 \pm 1.01 \mathrm{mV}, \boldsymbol{n}=8$ ). This fade in inhibitory synaptic transmission during the $5 \mathrm{~Hz}$ stimulation seems sufficient to account for the ability of $5 \mathrm{~Hz}$ stimulation to activate the NMDA receptor sufficiently to elicit depotentiation.

In addition to its low frequency of induction and dependence on NMDA receptor activation, depotentiation has several other interesting features. First, depotentiation is reversible. Within 30 min of successful depotentiation, a second train of tetanic stimulation could elicit clear LTP (Fig. 2A). Because the high-frequency stimulation protocol used in these experiments elicits near maximal LTP (T.J. O'Dell, unpubl.), this suggests that depotentiation represents a true erasure rather than a masking of LTP. Second, the ability of low-frequency stimulation to produce depotentiation is sensitive to stimulation frequency (Fujii et al. 1991; Larson et al. 1993). The same number of pulses, delivered at $10 \mathrm{~Hz}, 15 \mathrm{~min}$ after the induction of LTP, causes no depotentiation (EPSPs were $191.1 \pm 16.0 \%$ of baseline, $n=5$, $60 \mathrm{~min}$ after tetanic stimulation followed $15 \mathrm{~min}$ later by 900 pulses of stimulation at $10 \mathrm{~Hz}$ ).

What molecular mechanisms contribute to de-

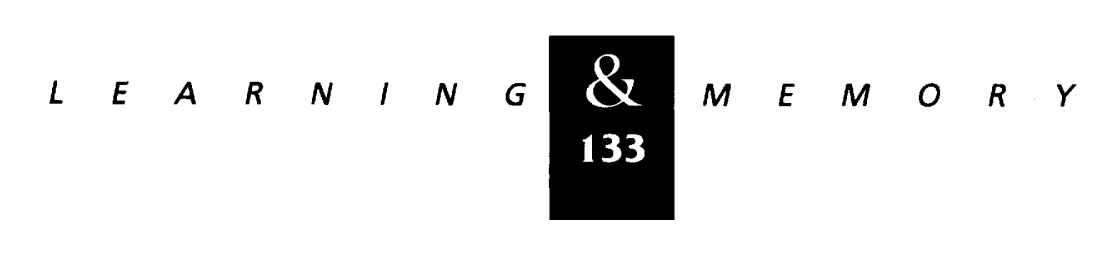


potentiation? Depotentiation can only be elicited during the early stages of LTP, a time during which the activity of a number of both serine/threonine and tyrosine kinases seems to be required to establish LTP (Bliss and Collingridge 1993). This overlapping time course suggests that $5 \mathrm{~Hz}$ stimulation may elicit depotentiation by interfering with the protein kinases required for LTP, perhaps by activating protein phosphatases. To test this idea, we examined the effects of two phosphatase inhibitors. Both okadaic acid (1.0 $\mu$; Fig. 4B) and calyculin A (1.0 $\mu \mathrm{M} ; n=4$; data not shown) blocked depotentiation completely while the inactive okadaic acid analog 1-nor-okadaone (1.0 $\mu \mathrm{M}$ ) had no effect on depotentiation (Fig. 4B). A lower concentration of okadaic acid ( $500 \mathrm{nM})$ had no effect on depotentiation; responses were $131 \pm 7.8 \%$ of baseline 60 min post-tetanus $(n=4)$ in experiments where 900 pulses of $5 \mathrm{~Hz}$ stimulation were given between 17 and 20 min post-tetanus.

If protein phosphatases can oppose the protein kinases that have become activated following the high-frequency tetanus that induces LTP, then perhaps $5 \mathrm{~Hz}$ stimulation just prior to the tetanus that induces LTP might prevent the initiation of LTP altogether. Indeed, 900 pulses at $5 \mathrm{~Hz}$ immediately before $100 \mathrm{~Hz}$ tetanic stimulation greatly suppressed LTP [Fig. 5; EPSPs were 124.0 $\pm 10.4 \%$ of baseline, $n=6,60 \mathrm{~min}$ following tetanic stimulation that was preceded by 900 stimulation pulses at $5 \mathrm{~Hz}, t(11)=3.42 ; P<0.01$ compared with LTP in control experiments $(187 \pm 14.7 \%$ of baseline, $n=6)]$. The effects of the $5 \mathrm{~Hz}$ stimulation were reversible. A second application of high-frequency stimulation $1 \mathrm{hr}$ later induced clear LTP. The ability of $5 \mathrm{~Hz}$ stimulation to suppress the initiation of LTP also appears to involve protein phosphatases, as it was completely blocked when calyculin A $(1.0 \mu \mathrm{M})$ was applied to the bath for $15 \mathrm{~min}$ prior to $5 \mathrm{~Hz}$ stimulation (Fig. 5B). In control experiments without a low-frequency train, LTP produced by $100 \mathrm{~Hz}$ stimulation was not affected by calyculin A [EPSPs $60 \mathrm{~min}$ post-tetanus were $168 \pm 23.3 \%$ of baseline, $n=5,5(10)=0.74$; not significant compared with $100 \mathrm{~Hz}$ stimulation in the absence of calyculin A]. The ability of $5 \mathrm{~Hz}$ stimulation delivered immediately prior to highfrequency stimulation to inhibit LTP is reminiscent of the ability of other manipulations that activate NMDA receptors prior to high frequency synaptic stimulation to inhibit LTP (Coan et al. 1989; Huang et al. 1992; Izumi et al. 1992a,b).
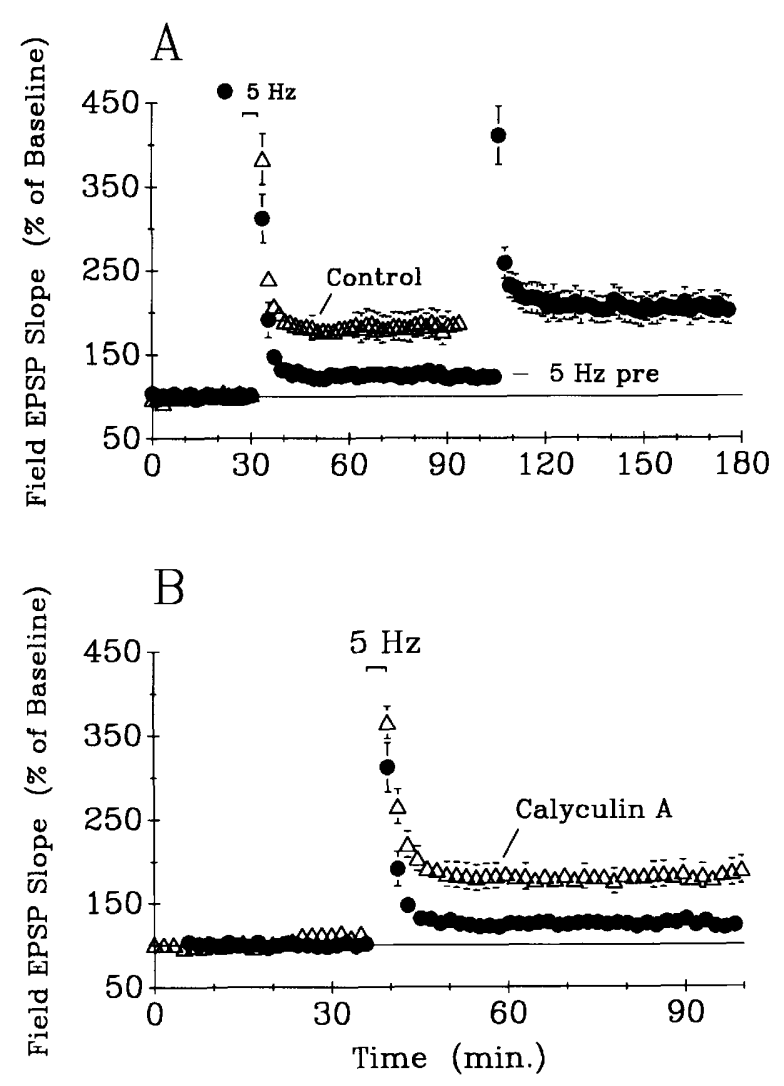

Figure 5: $5 \mathrm{~Hz}$ stimulation can suppress LTP when delivered immediately (within $5.0 \mathrm{~s}$ ) before high-frequency stimulation. (A) Inhibition of LTP by 900 pulses of $5 \mathrm{~Hz}$ stimulation delivered just before high-frequency stimulation $(O, n=6)$. A second pair of $100 \mathrm{~Hz}$ stimulation trains delivered in the same experiments $1 \mathrm{hr}$ later elicited clear LTP. Control experiments where no $5 \mathrm{~Hz}$ stimulation was delivered prior to tetanic stimulation are shown for comparison $(\triangle, n=7)$. In these experiments $100 \mathrm{~Hz}$ stimulation trains were delivered at the same intensity used to monitor baseline synaptic transmission (25\% of max.). (B) The phosphatase inhibitor calyculin A $(1.0 \mu \mathrm{M})$ blocks the ability of $5 \mathrm{~Hz}$ stimulation to inhibit LTP. Experiments from $A$ where 3 min of $5 \mathrm{~Hz}$ stimulation preceded high-frequency stimulation are shown $(O)$ along with experiments where $1.0 \mu \mathrm{M}$ calyculin $\mathrm{A}$ (in $0.02 \% \mathrm{DMSO}$ ) was present in the bath from $15 \mathrm{~min}$ prior to $5 \mathrm{~Hz}$ stimulation to $5 \mathrm{~min}$ post-tetanus $(\triangle, n=7)$. In the presence of calyculin A, $60 \mathrm{~min}$ following tetanic stimulation preceded by $5 \mathrm{~Hz}$ stimulation EPSPs were significantly larger $[t(11)=3.26, P<0.01]$ than when the same stimulation protocol was delivered in the absence of calyculin A.

The ability of inhibitors of protein phosphatases to prevent both the blockade of LTP before it is initiated and the depotentiation of LTP once it is induced suggests that $5 \mathrm{~Hz}$ stimulation

$$
\text { ……‥ }
$$


modulates LTP by opposing the action of protein kinases necessary for the induction of stable LTP. However, it is also possible that inhibiting protein phosphatases prevented depotentiation indirectly by altering synaptic transmission and changing the conditions necessary for the induction of depotentiation. We examined this possibility and found that $1.0 \mu \mathrm{M}$ okadaic acid had little effect on basal synaptic transmission (Fig. 4C), which is primarily mediated by non-NMDA-type glutamate receptors. We also observed no effect of $1.0 \mu \mathrm{M}$ okadaic acid on the pharmacologically isolated NMDA receptor-mediated component of the EPSPs (responses following a 20-min application of $1.0 \mu \mathrm{M}$ okadaic acid were $100.7 \pm 3.3 \%$ of baseline, $n=6$ ). Alternatively, okadaic acid might simply enhance potentiated synaptic transmission preferentially and thus mask depotentiation. However, a 20-min bath application of $1.0 \mu \mathrm{M}$ okadaic acid beginning $5 \mathrm{~min}$ post-tetanus had no effect on potentiated synaptic transmission $(n=6)$. Finally, if as our data suggests, the fade in inhibitory synaptic transmission during $5 \mathrm{~Hz}$ stimulation allows sufficient NMDA receptor activation to induce depotentiation, okadaic acid or APV might prevent depotentiation indirectly by modifying a property of inhibitory synaptic transmission that may be important for the induction of depotentiation. However, we found that the fade in inhibitory synaptic transmission was unchanged following a 15- to 20-min bath application of either $1.0 \mu \mathrm{M}$ okadaic acid or $50 \mu \mathrm{M}$ APV. For okadaic acid $(n=5)$, control IPSP amplitude $=6.41 \pm 1.98 \mathrm{mV}$; post $-5 \mathrm{~Hz}$ amplitude $=0.13 \pm 1.33 \mathrm{mV}$; for APV $(n=5)$, control IPSP amplitude $=6.56 \pm 1.41 \mathrm{mV}$; post $-5 \mathrm{~Hz}$ amplitude $=0.52 \pm 0.5 \mathrm{mV}$.

How does depotentiation compare with LTD? Because our results show that long trains of lowfrequency $(1-5 \mathrm{~Hz})$ stimulation in slices of adult guinea pig hippocampus do not induce LTD of basal synaptic transmission (see also Fujii et al. 1991), to compare LTD to potentiation we used slices obtained from young rats induced LTD with long trains of $1 \mathrm{~Hz}$ stimulation, conditions reported to be optimal for observing LTD (Dudek and Bear 1992, 1993; Mulkey and Malenka 1992). In the CA1 region of slices from young rats, 600 pulses of $1 \mathrm{~Hz}$ synaptic stimulation produced a pronounced and long-lasting depression of basal synaptic transmission (Fig. 6A). Fifty min following $1 \mathrm{~Hz}$ stimulation, EPSPs were reduced to $68.2 \pm 4.8 \%$ of baseline $[n=7, t(6)=6.58, P<0.01$ compared with pre-1 $\mathrm{Hz}$ baseline]. In agreement

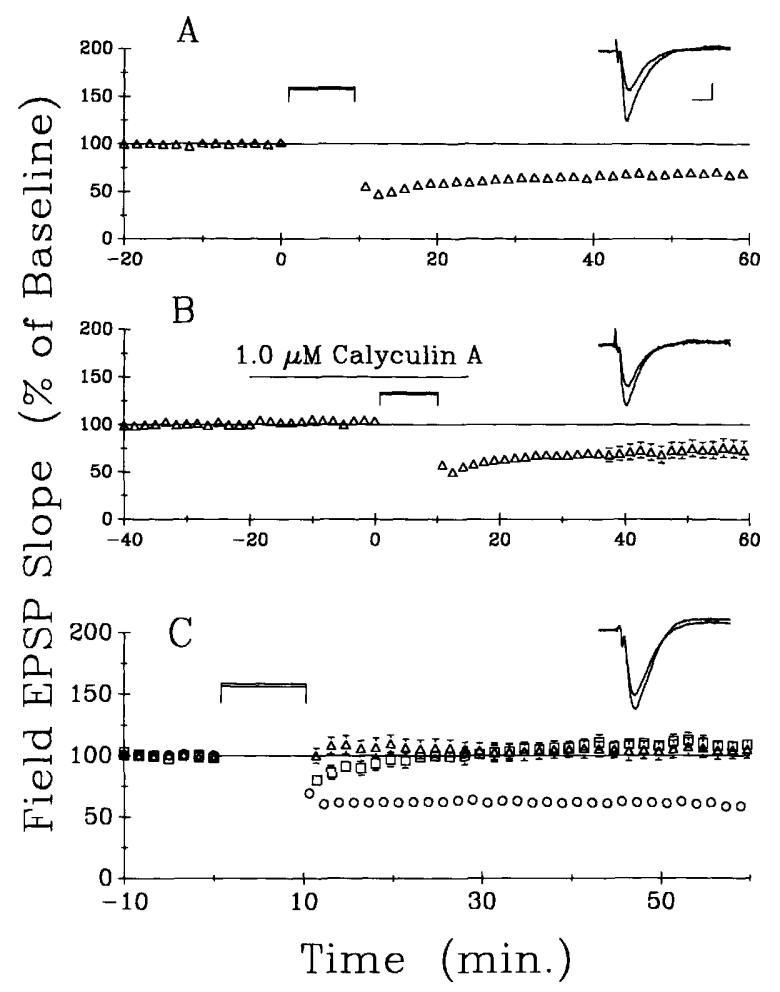

Figure 6: Effects of protein phosphatase inhibitors on homosynaptic LTD in young rat hippocampal slices. (A) Control experiments $(n=7)$ showing the depression of basal synaptic transmission produced by 600 pulses of 1 $\mathrm{Hz}$ stimulation (indicated by the bracket). Individual traces from one of the experiments showing EPSPs recorded just before (larger response) and $50 \mathrm{~min}$ after 1 $\mathrm{Hz}$ stimulation. Scale bars, $1.0 \mathrm{mV}$ and $5 \mathrm{msec}$. (B) Short applications of calyculin A $(1.0 \mu \mathrm{M})$ do not block LTD. Calyculin A was present in the bath for the duration indicated by the bar and 600 stimulation pulses at 1 $\mathrm{Hz}$ were delivered starting at time zero. EPSPs $50 \mathrm{~min}$ after $1 \mathrm{~Hz}$ stimulation in the presence of calyculin $\mathrm{A}$ were $73.1 \pm 9.3 \%$ of pre- $1 \mathrm{~Hz}$ levels $(n=5)$, and the amount of depression was not significantly different from the control experiments shown in $A[t(10)=0.49$, not significant]. Traces are EPSPs from one experiment recorded during control (larger) and $50 \mathrm{~min}$ after $1 \mathrm{~Hz}$ stimulation in calyculin A. (C) Long preincubations in phosphatase inhibitors block LTD. Slices were bathed in ACSF containing either $0.1 \%$ DMSO $(O, n=7), 1.0 \mu \mathrm{M}$ calyculin $A$ in $0.1 \%$ DMSO $(\square, n=4)$, or $1.0 \mu \mathrm{M}$ okadaic acid in $0.1 \%$ DMSO $(\triangle, n=5)$ for $1-3 \mathrm{hr}$ before beginning an experiment. After recording $10 \mathrm{~min}$ of baseline synaptic transmission, 600 stimulation pulses were delivered at $1 \mathrm{~Hz}$ (indicated by the bracket). In control experiments $(O)$ this produced a large and persistent LTD, whereas a small variable potentiation was induced by $1 \mathrm{~Hz}$ stimulation in slices treated with phosphatase inhibitors. Traces are EPSPs recorded during baseline and $50 \mathrm{~min}$ after $1 \mathrm{~Hz}$ stimulation (larger response) in a slice treated with $1.0 \mu \mathrm{m}$ calyculin $\mathrm{A}$.




with previous reports (Dudek and Bear 1992; Mulkey and Malenka 1992) we observed that LTD was inhibited by the NMDA receptor antagonist APV (EPSPs $50 \mathrm{~min}$ post-1 $\mathrm{Hz}$ stimulation in the presence of $50 \mu \mathrm{M}$ D,L-APV were not significantly depressed from baseline $[92.6 \pm 6.5 \%$ of baseline, $n=5, t(5)=1.14$, not significant compared with pre-1 $\mathrm{Hz}$ baseline]. However, a 30-min bath application of $1.0 \mu \mathrm{M}$ calyculin $\mathrm{A}$, which is sufficient to block depotentiation, had no effect on LTD (Fig. 6B). In contrast, in agreement with Mulkey et al. (1993) when slices are exposed to long periods of preincubation (1-3 hr) with $1.0 \mu \mathrm{M}$ okadaic acid or calyculin A, the phosphatase inhibitors blocked LTD in hippocampal slices from young rats (Fig. 6C).

\section{Discussion}

Our data suggest that two different patterns of activity in the Schaffer collaterals, both acting through the NMDA receptor, seem capable of initiating two different and opposing signaling cascades presumably by allowing different levels of $\mathrm{Ca}^{2+}$ influx into the postsynaptic cell. High-frequency stimulation at $100 \mathrm{~Hz}$ leads to a large increase of $\mathrm{Ca}^{2+}$ influx (estimated to be in the range of $1 \mu \mathrm{M}$ or higher), which triggers the cascade of serine-threonine and tyrosine protein kinases that lead to the induction of LTP (Bliss and Collingridge 1993). Low frequencies of stimulation, at 5 $\mathrm{Hz}$, presumably lead to a smaller $\mathrm{Ca}^{2+}$ influx, which seems to be integrated over time to trigger an opposing set of protein phosphatases capable of overriding and shutting off the kinase cascade. The phosphatase activity seems highly effective in its ability to override the kinase cascade. It not only inhibits the cascade after it has been triggered by the onset of LTP, but the phosphatase activity seems capable of preventing LTP from being generated when low-frequency stimulation is given prior to the induction of LTP.

Long trains of low-frequency synaptic stimulation can also depress basal synaptic transmission in the CA1 region of the hippocampus in young animals (Dudek and Bear 1992; Mulkey and Malenka 1992), but it does not reliably do so in adult animals (Figs. 1-3); Barrionuevo et al. 1980; Staubli and Lynch 1990; Fujii et al. 1991; Larson et al. 1993). However, as we and others (Barrionuevo et al. 1980; Staubli and Lynch 1990; Fujii et al. 1991; Larson et al. 1993) have observed, low-frequency stimulation can depress synaptic transmission in the adult hippocampus if synaptic transmission has recently undergone LTP. How, then, does depotentiation, the depression of potentiated synaptic transmission, relate to LTD, the depression of basal synaptic transmission? There are three major differences. First, depotentiation is robust in both young and adult animals, whereas LTD is most effective in young animals (Mulkey and Malenka 1992; Dudek and Bear 1993). In our experiments using adult guinea pig hippocampus we have not observed L'TD of basal synaptic transmission following low-frequency stimulation protocols that elicit LTD in young animals (cf. Figs. 1 and 6; see also Fujii et al. 1991). In contrast, depotentiation is present even in slices from mature animals. Second, although protein phosphatase inhibitors block both depotentiation and LTD, longer applications of calyculin A were required before LTD was inhibited, suggesting that depotentiation and LTD may involve phosphatases that differ in their sensitivity to these inhibitors. However, our results do not rule out the possibility that the same phosphatases are involved in LTD and depotentiation and that $5 \mathrm{~Hz}$ stimulation produces a lower level of phosphatase activation than $1 \mathrm{~Hz}$ stimulation and this lower level of activity is thus more sensitive to protein phosphatase inhibitors. Third, unlike LTD, depotentiation is dependent on both the current state of synaptic efficacy (LTP must have been induced) and the time interval following the induction of LTP (Fig. 1; see also Larson et al. 1993).

Despite these differences, LTD and depotentiation also share certain formal similarities. Both types of plasticity are induced by long trains of low-frequency synaptic stimulation and require NMDA receptor activation for their induction. Also, both are blocked by inhibitors of protein phosphatases. Thus, although depotentiation and LTD may be distinct processes, a more likely alternative is that the two types of plasticity are related or at least share common components. One possibility is that depotentiation and LTD are mechanistically the same and that developmental changes in the expression of other molecules render the basal state of adult synapses insensitive to the effects of low-frequency stimulation. In hippocampal slices from young animals the levels of $\mathrm{Ca}^{2+}$-independent, autophosphorylated $\mathrm{Ca}^{2+}$ / calmodulin kinase II (CAMKII) are higher than they are in slices from older animals (Molloy and Kennedy 1991) and levels of autophosphorylated

$$
\text { …… }
$$


CAMKII increase after the induction of LTP (Fukunaga et al. 1993). Perhaps the inability of protein phosphatase activation during low-frequency stimulation to depress basal synaptic transmission in adult hippocampus is the result of the reduction in levels of $\mathrm{Ca}^{2+}$-independent CAMKII activity that occurs during development.

The existence of presumably postsynaptic processes in the adult hippocampus that allow certain patterns of synaptic activity that have little effect on basal synaptic transmission to depress synaptic transmission following LTP is interesting from several points of view: behavioral, cell biological, molecular, and computational. From a behavioral perspective, depotentiation provides a potential molecular mechanism for the wellknown susceptibility of short-term memory processes to disruption or interference by distracting stimuli when these stimuli are given within minutes after learning (see, e.g., Muller and Pilzecker 1900). Although this interference with memory consolidation presumably occurs by means of a number of different molecular mechanisms, with different time courses, the ability of protein phosphatases to shut off the initiating cascade for LTP makes depotentiation a suitably rapid mechanism for disrupting memory processes at an early stage.

From a cell biological perspective, our data indicate that activating phosphatases in the postsynaptic cell can disrupt LTP during the first $20 \mathrm{~min}$. Because quantal analysis indicates that the presynaptic enhancement of transmitter release is recruited almost immediately after the onset of LTP (Bekkers and Stevens 1990; Malinow and Tsien 1990; Kullmann and Nicoll 1992; Larkman et al. 1992), there presumably must be continued communication, over these $20 \mathrm{~min}$, between the postsynaptic cell and the presynaptic terminal, perhaps by means of continued release of retrograde signals from the postsynaptic cell. Thus, the inductive process underlying the release of the retrograde signal and the establishment of stable LTP is more extended in time than is conventionally envisaged (for a similar view, see Stevens and Wang 1993). Although in some cases we observed a near complete depotentiation of LTP (Fig. 2A), on average a residual potentiation, of $\sim 50 \%$, still remained (Fig. 2C). This residual potentiation may in turn reflect a presynaptic component of LTP that is not susceptible to interruption by activation of postsynaptic processes. A quantal analysis of depotentiation may be revealing in this respect.

From a molecular perspective, the fact that depotentiation is dependent on the NMDA receptor suggests that increases in intracellular calcium via influx through the NMDA receptor ion channel are required. One candidate for an NMDA receptor-activated $\mathrm{Ca}^{2+}$-dependent protein phosphatase capable of eliciting depotentiation is the calcium/calmodulin-sensitive protein phosphatase calcineurin (Halpain and Greengard 1990). However, the concentrations of okadaic acid and calyculin A that effectively block depotentiation are too low to produce substantial inhibition of calcineurin (Hescheler et al. 1988). In contrast, these concentrations can fully inhibit other protein phosphatases, including protein phosphatase 1 (Hescheler et al. 1988; Ishihara et al. 1989; Cohen et al. 1990), the major protein phosphatase of the postsynaptic density (Shields et al. 1985). Perhaps low-frequency stimulation activates calcineurin, which in turn dephosphorylates regulatory proteins such as inhibitor 1 that activate protein phosphatase 1 (Lisman 1989). In hippocampal slices, the concentrations of okadaic acid and calyculin $\mathrm{A}$ that block depotentiation alter the activity of CAMKII, a serine/threonine protein kinase critical for LTP (Molloy and Kennedy 1991; Fukunaga et al. 1993). Thus, as suggested by Lisman (1989), the protein kinase cascade may be held in check dynamically by a cascade of protein phosphatases so that synaptic plasticity in the hippocampus is determined by the balance between these two cascades.

From a computational point of view, the finding that $5 \mathrm{~Hz}$ stimulation has opposite effects on basal as compared with potentiated synaptic transmission (Fig. 2B ) provides evidence in the hippocampus that the neurons in the CA1 region operate with a dynamic rather than a static modification threshold for producing changes in synaptic strength, a possibility first suggested on theoretical grounds by Bienenstock et al. (1982) and supported by recent experimental observations (Huang et al. 1992; Wexler and Stanton 1993). In

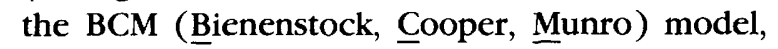
patterns of synaptic activity that depolarize the postsynaptic cell above a certain threshold result in potentiation, whereas patterns that produce depolarization below threshold produce depression. According to this view, the modification threshold is not fixed (Bear et al. 1987). It changes in response to the immediate history (and plastic state) of the synapse and will shift to a higher level when synapses are potentiated. Thus, patterns of synaptic activity that lie near the threshold can have

$$
\text { ….... }
$$


very different effects on synaptic strength depending on previous activity. In addition to our observations, support for this idea also comes from the work of Yang and Faber in the Mauthner cell, where the modification threshold also shifts with changes in synaptic efficacy (Yang and Faber 1991).

Finally, our data illustrate that like LTP and LTD, depotentiation is induced following activation of the NMDA receptor, a receptor that detects coincident pre- and postsynaptic activity (Bourne and Nicoll 1993). That coincidence alone is necessary but not sufficient to determine the sign of associative plasticity suggests that neither LTP nor depotentiation are truly Hebbian in nature. The critical feature for LTP is not simply a linear increase in synaptic strength following coincident activity in the pre- and postsynaptic cell, as coincidence can give rise to LTP, LTD, or depotentiation (Bienenstock et al. 1982; Lisman 1989; Tsumoto 1993). The critical factor that distinguishes LTP from depotentiation is that each requires a different level of a common postsynaptic signal, presumably $\mathrm{Ca}^{2+}$ influx, driven by different degrees of presynaptic activity. Our data suggest that low levels of this signal $\left(\mathrm{Ca}^{2+}\right.$ influx ) may preferentially activate phosphatases (Kasai 1993). To activate the kinases, a rapid rise of $\mathrm{Ca}^{2+}$ to high levels seems to be required (Malenka 1991).

The signal transduction pathways that underlie LTP appear complex, involving multiple protein kinases and perhaps one or more retrograde messengers (Bliss and Collingridge 1993). This complex and highly regulated molecular mechanism for controlling synaptic strength may be required to allow multiple sites for modulation and error correction. We would argue that depotentiation represents one mechanism whereby the convergence of different signal transduction pathways can modulate LTP and presumably enhance the information storage capabilities of hippocampal synapses.

\section{Acknowledgments}

E.R.K. is a senior investigator and T.J.O. was an associate of the Howard Hughes Medical Institute; this work was also supported by National Institute of Mental Health grant $\mathrm{MH}-45923$, and the National Institute on Aging Alzheimer's Disease Research Center of New York at Columbia University.

The publication costs of this article were defrayed in part by payment of page charges. This article must therefore be hereby marked "advertisement" in accordance with 18 USC section 1734 solely to indicate this fact.

\section{References}

Barrionuevo, G., F. Schottler, and G. Lynch. 1980 The effects of repetitive low hippocampus. Life Sci. 27: 2385-2391.

Bear, M.F., L.N. Cooper, and F.F. Ebner. 1987. A physiological basis for a theory of synapse modification. Science 237: 42-48.

Bekkers, J.M. and C.F. Stevens. 1990. Presynaptic mechanisms for long-term potentiation in the hippocampus. Nature 346: 724-729.

Bienenstock, E.L., L.N. Cooper, and P.W. Munro. 1982. Theory for the visual cortex. J. Neurosci. 2: 32-48.

Bliss, T.V.P. and G.L. Collingridge. 1993. A synaptic model of memory: Long-term potentiation in the hippocampus. Nature 361: 31-39.

Bolshakov, V.Y. and S.A. Siegelbaum. 1994. Postsynaptic induction and presynaptic expression of hippocampal long-term depression. Science 264: 1148-1152.

Bourne, H.R. and R.A. Nicoll. 1993. Molecular machines integrate coincident synaptic signals. Neuron 10: 65-75.

Coan, E.J., A.J. Irving, and G.L. Collingridge. 1989. Low-frequency activation of the NMDA receptor system can prevent the induction of LTP. Neurosci. Lett. 105: 205-210.

Cohen, R., C.F.B. Holmes, and Y. Tsukitani. 1990. Okadaic acid: A new probe for the study of cellular regulation. Trends Biochem. Sci. 15: 98-102.

Davies, C.H., S.J. Starkey, M.F. Pozza, and G.L. Collingridge. 1991. $\mathrm{GABA}_{\mathrm{B}}$ autoreceptors regulate the induction of LTP. Nature 349: 609-611.

Dudek, S.M. and M.F. Bear. 1992. Homosynaptic long-term depression in area CA1 of hippocampus and effect of $\mathrm{N}$-methyl-D-aspartate receptor blockade. Proc. Natl. Acad. Sci. 89: 4343-4367.

1993. Bidirectional long-term modification of synaptic effectiveness in adult and immature hippocampus. J. Neurosci. 13: 2910-2918.

Fujii, S., K. Saito, H. Miyakawa, K. Ito, and H. Kato. 1991. Reversal of long-term potentiation (depotentiation) induced by tetanus stimulation of the input to CA1 neurons of guinea pig hippocampal slices. Brain Res. 555: 112-122.

Fukunaga, K., L. Stoppini, E. Miyamoto, and D. Muller. 1993. Long-term potentiation is associated with an increased activity of $\mathrm{Ca}^{2+} /$ calmodulin-dependent protein kinase II. I. Biol. Chem. 268: 7863-7867.

Halpain, S. and P. Greengard. 1990. Activation of NMDA receptor induces rapid dephosphorylation of the cytoskeletal protein MAP2. Neuron 5: 237-246.

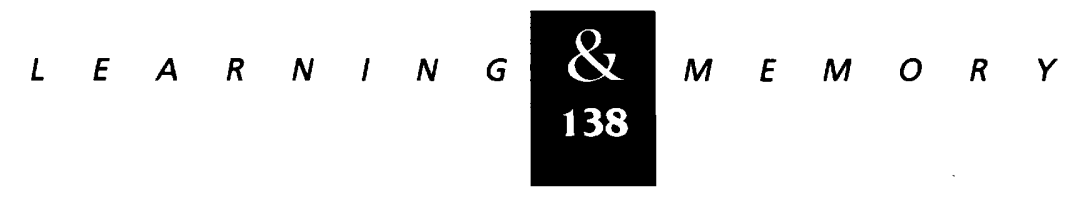


Hescheler, J., G. Mieskes, J.C. Ruegg, A. Takai, and W. Trautwein. 1988. Effects of a protein phosphatase inhibitor, okadaic acid, on membrane currents of isolated guinea-pig cardiac myocytes. Pflugers Arch. 412: 248-252.

Huang, Y.-Y., A. Colino, D.K. Selig, and R.C. Malenka. 1992. The influence of prior synaptic activity on the induction of long-term potentiation. Science 255: 730-733.

Ishihara, H., B.L. Martin, D.L. Brautigan, H. Karaki, H. Ozaki, Y. Kato, N. Fusetani, S. Watabe, K. Hashimoto, D. Uemura, and D.J. Hartshorne. 1989. Calyculin A and okadaic acid: Inhibitors of protein phosphatase activity. Biochem. Biophys. Res. Comm. 159: 871-877.

Izumi, Y., D.B. Clifford, and C.F. Zorumski. 1992a. Low concentrations of $\mathrm{N}$-methyl-D-aspartate inhibit the induction of long-term potentiation in rat hippocampal slices. Neurosci. Lett. 137: 245-248.

1992b. Inhibition of long-term potentiation by NMDA-mediated nitric oxide release. Science 257: 1273-1276.

Kasai, H. 1993. Cytosolic Ca2 ${ }^{+}$gradients, $\mathrm{Ca}^{2+}$ binding proteins and synaptic plasticity. Neurosci. Res. 16: 1-7.

Kullmann, D.M. and R.A. Nicoll. 1992. Long-term potentiation is associated with increases in both quantal content and quantal amplitude. Nature 357: 240-244.

Larkman, A., T. Hannay, K. Stratford, and J. Jack. 1992. Presynaptic release probability influences the locus of long-term potentiation. Nature 360: 70-73.

Larson, J., P. Xiao, and G. Lynch. 1993. Reversal of LTP by theta frequency stimulation. Brain Res. 600: 97-102.

Lisman, J. 1989. A mechanism for the Hebb and the anti-Hebb processes underlying learning and Memory. Proc. Natl. Acad. Sci. 86: 9574-9578.

Malenka, R.C. 1991. Postsynaptic factors control the duration of synaptic enhancement in area CA1 of the hippocampus. Neuron 6: 53-60.

Malenka, R.C. and R.A. Nicoll. 1993. NMDA-receptor dependent synaptic plasticity: Multiple forms and mechanisms. Trends Neurosci. 16: 521-527.

Malinow, R. and R.W. Tsien. 1990. Presynaptic enhancement shown by whole-cell recordings of long-term potentiation in hippocampal slices. Nature 346: 177-180.

McCarren, M. and B.E. Alger. 1985. Use-dependent depression of IPSPs in rat hippocampal pyramidal cells in vitro. J. Neurophysiol. 52: 557-571.

Molloy, S.S. and M.B. Kennedy. 1991. Autophosphorylation of type $1 \mathrm{C} \mathrm{Ca}^{2+} /$ calmodulin-dependent protein kinase in cultures of postnatal rat hippocampal slices. Proc. Natl. Acad. Sci. 88: 4756-4760.
Mott, D.D. and D.V. Lewis. 1991. Facilitation of the induction of long-term potentiation by $\mathrm{GABA}_{\mathrm{B}}$ receptors. Science 252: 1718-1720.

Mulkey, R.M. and R.C. Malenka. 1992. Mechanisms underlying induction of homosynaptic long-term depression in area CA1 of the hippocampus. Neuron 9: 967-975.

Mulkey, R.M., C.E. Herron, and R.C. Malenka. 1993. An essential role for protein phosphatases in hippocampal long-term depression. Science 261: 1051-1055.

Muller, G.E. and A. Pilzecker. 1900. Experimentelle Beitrage zur Lehre vom Gedachtni. Z. Psychol. 1: 1-300.

Pacelli, G.J., W. Su, and S.R. Kelso. 1991. Activity-induced decrease in early and late inhibitory synaptic conductances in hippocampus. Synapse 7: 1-13.

Sah, P., S. Hestrin, and R.A. Nicoll. 1989. Tonic activation of NMDA receptors by ambient glutamate enhances excitability of neurons. Science 246: 815-818.

Sejnowski, T. 1977. Storing covariance with nonlineraly interacting neurons. I. Math. Biol. 4: 303-321.

Shields, S.M., T.S. Ingebritsen, and P.T. Kelly. 1985. Identification of protein phosphatase 1 in synaptic junction: Dephosphorylation of endogenous calmodulin-dependent kinase II and synapse-enriched phosphoproteins. J. Neurosci. 5: 3114-3422.

Staubli, U. and G. Lynch. 1990. Stable depression of potentiated synaptic responses in hippocampus with $1-5 \mathrm{~Hz}$ stimulation. Brain Res. 513: 113-118.

Stevens, C.F. and Y. Wang. 1993. Reversal of long-term potentiation by inhibitors of haemoxygenase. Nature 364: $147-149$.

Tsumoto, T. 1993. Long-term depression in cerebral cortex: A possible substrate of "forgetting" that should not be forgotten. Neurosci. Res. 16: 263-270.

Wexler, E.M. and P.K. Stanton. 1993. Priming of homosynaptic long-term depression in hippocampus by previous synaptic activity. NeuroReport 4: 591-594.

Wilshaw, D. and P. Dayan. 1990. Optimal plasticity from matrix memories: What goes up must come down. Neural Comput. 2: 85-93.

Wilcox, K.S. and M.A. Dichter. 1994. Paired pulse depression in cultured hippocampal neurons is due to a presynaptic mechanism independent of $\mathrm{GABA}_{\mathrm{B}}$ autoreceptor activation. J. Neurosci. 14: 1775-1788.

Yang, X.-D. and D.S. Faber. 1991. Initial synaptic efficacy influences induction and expression of long-term changes in transmission. Proc. Natl. Acad. Sci. 88: 4299-4304.

Received May 3, 1994; accepted in revised form July 11, 1994.

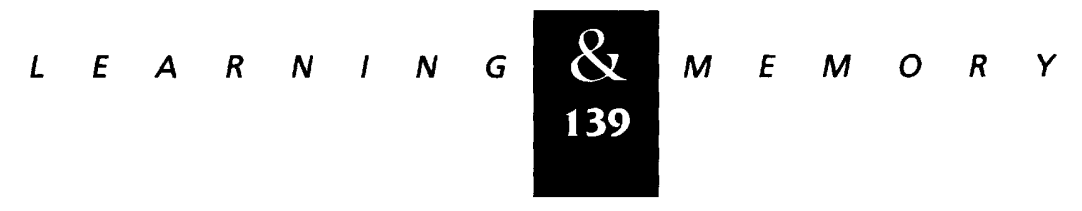




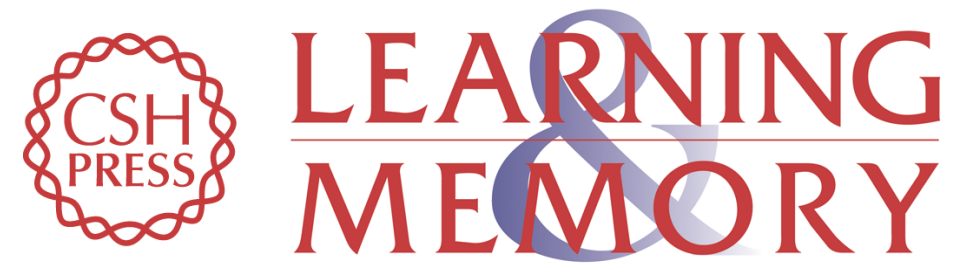

\section{Low-frequency stimulation erases LTP through an NMDA receptor-mediated activation of protein phosphatases.}

T J O'Dell and E R Kandel

Learn. Mem. 1994, 1:

Access the most recent version at doi:10.1101//m.1.2.129

References This article cites 45 articles, 15 of which can be accessed free at: http://learnmem.cshlp.org/content/1/2/129.full.html\#ref-list-1

License

Email Alerting Receive free email alerts when new articles cite this article - sign up in the box at the Service top right corner of the article or click here. 